\title{
Paradoxical reaction in male breast tuberculosis
}

\author{
Sibel Işlak Mutcal, Abdurrahman Kaya*, Mustafa Alkan, Yusuf Emre Özdemir and Sibel Yıldız Kaya \\ Department of Infectious Diseases, Cerrahpasa, Istanbul University, Turkey
}

\begin{abstract}
28-year-old man was admitted to our clinic with complaints of the left breast discharge and swelling for about one year. Although many antibiotics had been given, it had not been responded to the empirical antimicrobials. Mycobacterium tuberculosis was grown in culture after 28 days. While everything was going better in the course of the treatment, the erythematous and purulent lymph node that spontaneously drained was acutely appeared in the right axillary fossa after 45 days. We considered as Paradoxical reaction and then continued the therapy. The patient recovered and no with recurrence.
\end{abstract}

\section{Case}

28-year-old man was admitted to our clinic with complaints of the left breast discharge and swelling for about one year. In his medical history, the lesion had been drained and cultured several times. Although many antibiotics had been given, it had not been responded to the empirical antimicrobials and the bacterial cultures had remained sterile. Afterwards weight loss, subfebril fever and night sweats had been accompanied by these complaints. Due to abdominal pain, abdominal ultrasound was performed, multiple lymphadenopathies (LAP) were detected over $10 \mathrm{~mm}$ around sites of portocaval and pancreas. The chest radiography was unremarkable. On laboratory as follow: White blood cell:11500, sedimentation rate: 72/hour, C-reactive protein: $28 \mathrm{mg} / \mathrm{L}$ and anti-HIV: negative. The culture was obtained again from breast discharge. Acid-fast-bacilli were seen on smear and the patient was considered as disseminated tuberculosis (TB) presenting with breast involvement. Therefore, anti-tuberculosis treatment was initiated. Mycobacterium tuberculosis was grown in Lövenstein-Jensen media and Mgit culture after 28 days. While everything was going better in the course of the treatment, the erythematous and purulent lymph nodes reaching $26 \mathrm{x} 8 \mathrm{~mm}$ in size that spontaneously drained was acutely appeared in the right axillary fossa after 45 days (Figure 1). They were tender to palpation and fistula formation was appeared from the enlarged lymph nodes. The discharge of the fistula was cultured and examined under microscopy. Acid-fast-bacilli were not seen, and mycobacterium tuberculosis was not grown in the samples. Therefore, the clinical case was considered as paradox reaction. We continued therapy. The complaints, discharge and enlarged LAP were fully regressed. The patient recovered, and the treatment was discontinued in the end of 12 months. On 3-years follow-up, the patient was doing well, with no recurrence and no sequelae.

Tuberculosis of the breast is very rare in male. Paradoxical reaction (PR) is an immune reaction to lysis of tuberculosis bacilli and is defined

Copyright: (C2018 Mutcalı SI. This is an open-access article distributed under the terms of the Creative Commons Attribution License, which permits unrestricted use, distribution, and reproduction in any medium, provided the original author and source are credited.

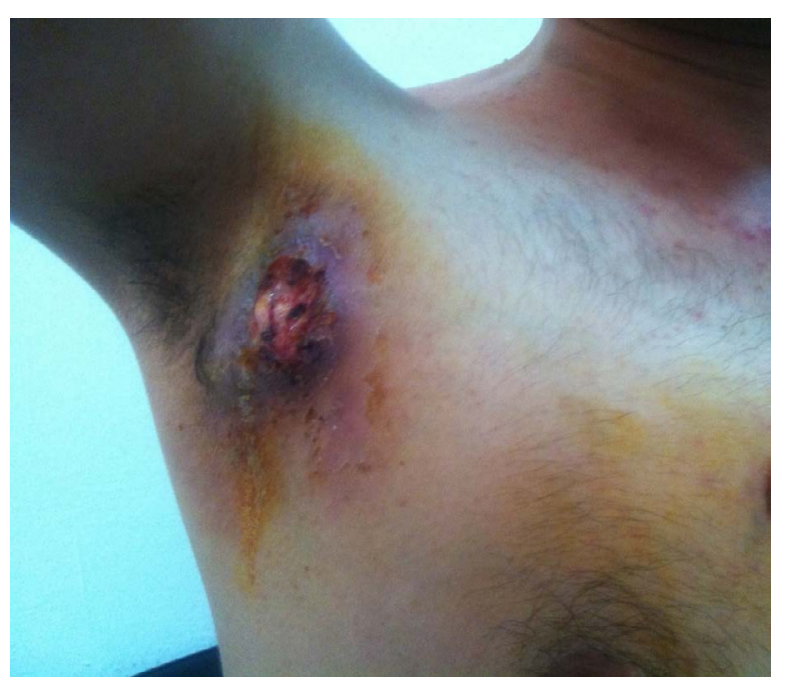

Figure 1. The erythematous and purulent lymph node induced by paradoxial reaction

as worsening of pre-existing tuberculosis lesions or the emergence of new lesions [1]. It can be diagnosed after excluding other differential causes such as drug resistance, another infection, side effect of the drug, treatment failure [2]. PR should be kept in mind during treatment of tuberculosis.

\section{References}

1. Smith H (1987) Paradoxical responses during the chemotherapy of tuberculosis. $J$ Infect 15: 1-3.

2. Cheng VC, Ho PL, Lee RA, Chan KS, Chan KK, et al. (2002) Clinical spectrum of paradoxical deterioration during antituberculosis therapy in non-HIV infected patients. Eur J Clin Microbiol Infect Dis 21: 803-9.

${ }^{\star}$ Correspondence to: Abdurrahman Kaya, Department of Infectious Disease, Medical School of Cerrahpasa, Istanbul University, Turkey, Tel: 905066113328 , Fax: 902126320050, E-mail: dr.abdkaya@hotmail.com

Key words: paradoxical reaction, tuberculosis, breast

Received: August 06, 2018; Accepted: September 03, 2018; Published: September 07, 2018 